\title{
Autogestão e subjetividade: interfaces e desafios na visão de especialistas da ANTEAG, UNISOL e UNITRABALHO
}

\author{
Self-management and subjectivity: interfaces and challenges in the perspective of experts \\ from ANTEAG, UNISOL and UNITRABALHO
}

Fernanda Mitsue Soares Onuma ${ }^{1}$

Flávia Luciana Naves Mafra ${ }^{2}$

Lilian Barros Moreira ${ }^{3}$

\section{Resumo}

A Administração, em sua corrente teórica dominante, tem se prestado a transformar as empresas em espaços de propagação ideológica acerca de formas hierarquizadas de organização e gestão do trabalho. Negando esta dimensão política e ideológica da ação administrativa, a Teoria da Administração tem se tornado cúmplice dos interesses do business, educando profissionais cujas ações acabam sobrepondo o econômico ao fator humano e às questões éticas. Em contraposição a este cenário de injustiça e exploração, encontra-se a autogestão, forma de gestão não hierarquizada e democrática cuja implantação tem enfrentado muita dificuldade. Para buscar compreender os desafios que se impõem aos trabalhadores e trabalhadoras que se propõem a trabalhar de maneira autogestionária, foram realizadas entrevistas semi-estruturadas com um especialista em cada uma das três seguintes entidades de fomento a organizações autogestionárias: ANTEAG, UNISOL e UNITRABALHO. Os dados foram analisados por meio do método de análise de conteúdo e indicaram que a autogestão, na visão destes profissionais, implica necessidade de uma mudança de subjetividade desses trabalhadores e trabalhadoras, acostumados ao modelo de trabalho hierarquizado e não democrático. Com base nisso, argumenta-se que, para uma melhor compreensão da dificuldade de implantação da autogestão nas organizações, é necessária a adoção de um conceito de subjetividade que englobe não só o seu caráter individual, mas também seu caráter coletivo. Conquanto a visão da subjetividade individual e coletiva nos leve a refletir sobre o fato de que os desafios da prática da autogestão são mais profundos do que aparentam inicialmente, acreditamos que sua resolução pode estar mais próxima de nós do que imaginamos.

Palavras-chave: Autogestão. Subjetividade. Economia solidária.

\section{Abstract}

According to its mainstream approach, management has turned organizations into hierarchical forms of organization and work management. By denying its political and ideological dimensions, the Management Theory has become part of the

Artigo submetido em 14 de setembro de 2010 e aceito para publicação em 22 de março de 2011.

1 Doutoranda em Administração pela Universidade Federal do Rio Grande do Sul (PPGA/UFRGS); Mestre em Administração pela Universidade Federal de Lavras (PPGA/UFLA). Endereço: Rua Washington Luiz, 855 - Centro, CEP 90010-460, Porto Alegre - RS, Brasil. E-mail: feonuma@gmail.com

2 Professora Adjunta do Departamento de Administração e Economia da Universidade Federal de Lavras (DAE/UFLA); Doutora em Ciências Sociais pelo CPDA/UFFRJ. Endereço: Campus Universitário da UFLA, Caixa Postal 3037, CEP 37200-000, Lavras - MG, Brasil. E-mail: flanaves@dae.ufla.br

${ }^{3}$ Doutoranda em Administração pela Universidade Federal do Rio Grande do Sul (PPGA/UFRGS); Mestre em Administração pela Universidade Federal de Lavras (PPGA/UFLA). Endereço: Rua Washington Luiz, 855 - Centro, CEP 90010-460, Porto Alegre - RS, Brasil. E-mail: lilibmoreira@gmail.com 
business concerns, teaching professionals how to act according to an instrumental rationality. In counterpoint to this scenario of injustice and exploitation, self-management arises, a form of management that is democratic and nonhierarchical, despite the drawbacks that still remain. The goal of this work is to understand the challenges that the workers who chose to work under the self-management concept face. We interviewed specialists from three organizations - ANTEAG, UNISOL and UNITRABALHO. The interviews were analyzed through the method of content analysis. For these professionals, self-management implies a need for a change in the subjectivity in the workers, who are used to a hierarchical and non-democratic kind of work. We argue that in order to understand the difficulty of implementing self-management in organizations, a concept of subjectivity that embraces not only the individual but also the collective feature should be adopted. The concept of subjectivity as being both individual and collective suggests that the challenges encountered in the practice of self-management are deeper than they first appear to be, although they might be solved sooner than we think.

Keywords: Self-management. Subjectivity. Solidary Economy.

\section{Introdução}

A Teoria Administrativa corrente transformou seu vocabulário ao longo das mudanças sociais históricas, reavaliando conceitos. Por exemplo, "funcionários" passaram a "colaboradores" e administração de "recursos humanos" passou a "gestão de pessoas". Isso mostra uma mudança de consciência do papel das pessoas nas organizações. Contudo, a prática das empresas tem mostrado que essas transformações têm ocorrido somente no plano do discurso, de modo que as transformações conceituais da área acabam por constituir meros eufemismos.

Corroborando esta visão, Tragtenberg (1989, p. 17) acusa a política de relações humanas de ser "excessivamente polida para ser honesta" e de consistir em um elemento "simplificador e idealista, manipulador e realista", que promove ideologicamente o conformismo, contra o qual os trabalhadores e trabalhadoras manifestam uma reação reivindicatória. A política de relações humanas, segundo o autor, não tem o objetivo de anular o peso das relações sociais, mas, como expresso no "jargão da escola", de "formar em profundidade", delegando à empresa e aos seus conselheiros o papel dessa formação (TRAGTENBERG, 1989, p. 17).

A empresa passa a ser não só o lugar físico em que se trabalha, "onde o trabalho excedente cresce às expensas do necessário", lugar de oposição de classes, mas também "o cenário da inculcação ideológica" (TRAGTENBERG, 1989, p. 25). Motta et al. (1993, p. 69-70) complementam esta ideia ao afirmarem que as empresas constituem "o sistema social mais formalizado da sociedade, sendo, portanto, um sistema de significativas condutas institucionalizadas", de modo que, para os autores, mais do que bens, as empresas produzem "formas de raciocínio e de comportamento", daí a importância do estudo de novas formas organizacionais, que se pautem por novos valores que possibilitem a superação da situação de dominação estabelecida entre chefes e empregados nas empresas estruturadas segundo formas organizacionais hierárquicas.

Estudos anteriores mostram como as práticas administrativas tradicionais, como as de gestão de pessoas, têm servido, desde o surgimento da Administração Científica, como apontado por Harvey (1998), para o controle dos trabalhadores e trabalhadoras com vistas ao aumento da eficiência das empresas. Townley (1993) apresenta como exemplo a Administração de Recursos Humanos (ARH), que, dentro da perspectiva funcionalista predominante, é encarada como a "caixa preta" da produção, visto que os funcionários, inputs (entradas) das organizações, são selecionados, treinados, desenvolvidos e remunerados a fim de gerarem o trabalho, outputs (resultados) da empresa. Ou seja, sob essa ótica, a ARH é vista como responsável pela manutenção do sistema organizacional e instrumento para o alcance de eficiência, tal como sugere a psicologia behaviorista em estudos de gestão de pessoas. 
Portanto, discutir a questão do trabalho dentro das organizações autogestionárias, com base em uma reavaliação dos valores da própria Administração e se pautando no estabelecimento de novos vínculos sociais em meio às relações interpessoais e de trabalho tecidas nas organizações pode trazer grande contribuição à Teoria Administrativa ao apontar a potencialidade de práticas administrativas que se propõem a superar a questão da alienação e do poder disciplinar decorrentes de formas hierarquizadas de gestão.

Contudo, conforme estudos apontam, a mudança de valores dentro das organizações não é uma tarefa fácil (BARRETO e PAES DE PAULA, 2009; COSTA et al., 2008; DAL MAGRO e COUTINHO, 2008; NARDI et al., 2006; OLIVEIRA, 2007), pois implica a necessidade de uma transformação da subjetividade de pessoas socializadas dentro de uma sociedade que defende valores predominantemente capitalistas em relação à produção, gestão e trabalho (LOURENÇO, 2008; PINTO, 2006).

Assim, estudos que se proponham, como este, a discutir a questão da subjetividade dos trabalhadores e trabalhadoras de empresas autogestionárias podem, também, fornecer novos elementos para a discussão dos desafios enfrentados pela autogestão e sua efetiva implantação nas organizações. Neste trabalho, tem-se por objetivo compreender os desafios da prática da autogestão nas organizações por meio do relato da experiência de três especialistas em autogestão para que, então, tais desafios sejam discutidos buscando-se apontar possíveis caminhos para sua superação. O problema de pesquisa que este trabalho se propõe a investigar é: a noção de subjetividade individual e coletiva, proposta por Domingues (1999) e Elias (1994) pode contribuir para a discussão dos desafios à prática da autogestão nas organizações, apontados por especialistas no tema?

Para responder a essa questão, realizamos entrevistas com especialistas que integram o quadro de profissionais de cada uma das três organizações de fomento a organizações de Economia Solidária que compuseram nosso estudo: Associação Nacional de Trabalhadores e Empresas de Autogestão e Participação Acionária (ANTEAG), União e Solidariedade das Cooperativas e Empreendimentos de Economia Social do Brasil (UNISOL) e Fundação Interuniversitária de Estudos e Pesquisas sobre o Trabalho (UNITRABALHO). Com o relato dessas pessoas, percebeu-se a necessidade de discutir a importância da noção de subjetividade, que acabou surgindo de forma implícita no discurso desses especialistas. Tomando por base os conceitos de subjetividade presentes em Domingues (1999) e Elias (1994), apresenta-se aqui, como argumento, que a subjetividade não é apenas dotada de dimensão individual, como é comumente discutida, mas também de uma dimensão coletiva, sendo essa interface entre estrutura e agência necessária para a discussão dos desafios da autogestão apontados pelos especialistas.

\section{A Teoria Administrativa Dominante e sua Influência nos Valores Sociais}

Aktouf (2004) afirma que as práticas atuais em Administração refletem os interesses do business, de modo que tanto a ciência administrativa quanto suas escolas têm se prestado a expandir o domínio das grandes corporações por meio da imposição do que seria uma "educação legítima" em Administração.

Essa forma de educação consiste na divulgação, tanto em meio acadêmico quanto dentro das organizações, das teorias administrativas de origem anglo-saxônica, as quais priorizam a formação instrumental - baseada no cálculo e no que Aktouf (2004) chama de "financiarização" administrativa - em detrimento de uma formação humanística, que cobre tanto dos pesquisadores quanto dos profissionais da área a busca por uma postura ética e socialmente responsável na condução das organizações.

Essa prioridade concedida ao saber matemático dentro da Administração reitera a proposição de Sousa Santos (2009) de que a ciência não é neutra, como mostra também o "economicismo" predominante nas ciências administrativas, tal como argumenta Aktouf (2004). Para este autor, em conformidade com a "lei da queda tendencial das taxas de lucro" do pensamento marxista e com o pensamento de Bernard Maris, se, 
antes, as organizações geravam empregos por meio de seus lucros, hoje, o desemprego é que fornece lucros às empresas. A primazia pelo saber matemático é apontada por Sousa Santos (2009) como característica do paradigma dominante nas ciências, alinhado ao pensamento positivista.

Essa racionalidade instrumental tem sido prejudicial às pessoas no âmbito das organizações, servindo de prerrogativa ao controle exagerado. As hierarquias e o controle nas organizações têm sido justificados, tanto dentro das empresas quanto na literatura da Teoria Administrativa, como formas naturalizadas e, portanto, legítimas de exercício do poder no âmbito das relações de trabalho. Situação que permanece mesmo diante de mudanças do pensamento da sociedade em relação ao discurso do trabalho, passando do modelo de produção em massa taylorista/fordista à produção flexível toyotista, em virtude de transformações do contexto histórico e na forma de se produzirem bens e conhecimentos que foram possíveis graças a inovações sistêmicas nos modelos organizacionais (MACKE, 2005).

A industrialização e a modernização das economias nacionais ao redor do mundo trouxeram grandes mudanças ao trabalho humano. A própria natureza do trabalho industrial, com a produção em série e a utilização de máquinas, intensificou a produção em centros onde as unidades fabris se concentravam, acelerando o processo de urbanização que, aliado ao crescimento demográfico registrado a partir do século XIX, trouxe graves consequências a grande parte da população mundial (ALBORNOZ, 1992).

Com o advento da industrialização e sua evolução ao longo da história, passou-se da produção em massa, caracterizada pelo modelo taylorista/fordista, pela rígida divisão e controle do trabalho, para formas que buscaram resgatar o aspecto humano do trabalho, preocupação esta inaugurada pelos trabalhos da Escola das Relações Humanas, que influenciaram formas atuais, buscando maior flexibilização tanto na produção quanto nas relações de trabalho, a exemplo do modelo toyotista de produção ou dos modelos das "novas burocracias". Contudo, estudos como os de Child e Mcgrath (2001) e Dellagnelo e Machado-da-Silva (2000) têm apontado que, apesar da mudança no discurso da sociedade para uma tônica mais humanizante em relação ao contexto histórico e social da época em que o modelo burocrático surgiu, o modelo taylorista/fordista prevalece soberano nas organizações, ainda que indiretamente.

Pesquisadores como Johnson (2006) encontram explicações para esse fato. Segundo este autor, o argumento da eficiência econômica tem sido utilizado a fim de minar a emergência de novas formas organizacionais mais democráticas, que propõem, ao contrário do que ocorre no modelo burocrático, decisões compartilhadas e que os trabalhadores deixem de ser meros executores de tarefas em uma situação de alienação passem a proprietários ou co-responsáveis pela administração da organização. Deste modo, apesar da tônica do discurso pós-moderno dentro da academia e das próprias organizações, muitas das características do modelo de produção em massa ainda podem ser observadas nas organizações atuais. Em virtude de "certo esgotamento dos esforços modelísticos", a teoria das organizações tem se voltado à questão da subjetividade, numa tentativa de colocar "as organizações a serviço dos seres humanos e não o contrário" (VOLNOVICH, 1995, p. 61).

A primazia de organizações hierárquicas e antidemocráticas, em que podemos enxergar o homem a serviço da organização, tais como o modelo burocrático, permanece, apesar da emergência dessas novas formas organizacionais, e está fortemente ligada à adequação entre a racionalidade instrumental defendida por esta e a crença capitalista, que enfatiza o alcance utilitário de lucros em detrimento do bem-estar social. Ainda é preciso destacar a influência das teorias de origem anglo-saxônica, marcadas por essa mentalidade, em um processo favorecido pela globalização.

Em contrapartida a este cenário, surge a crítica à Teoria Administrativa, que não busca desconstruir a Administração, pois, como ressalta Gaulejac (2007), a gestão não é maléfica por si só, visto que é necessária e benéfica à organização da produção. O problema reside no extremado pragmatismo que passou a imperar na Administração com a primazia do econômico sobre o social, como ressalta Dejours (2007). Contudo, 
embora as mudanças no âmbito da sociedade sejam bastante difíceis, não são impossíveis, existindo novas formas de se pensar a gestão organizacional, a exemplo da autogestão, como será demonstrado a seguir.

\section{Um Contraponto à Teoria Administrativa Dominante: a Autogestão}

Diante do panorama da Teoria Administrativa apresentado anteriormente, pode-se perguntar: haveria, então, espaço para novas formas organizacionais que se oponham a tais modelos tradicionais de gestão, formas que busquem uma "organização a serviço das pessoas", como proposto por Volnovich (1995)? Acredita-se que sim, visto que, mesmo diante desse cenário de predominância de modelos organizacionais hierárquicos, surgiram novas propostas de organização do trabalho, como a autogestão.

Para Lechat e Barcelos (2008, p. 97), "autogestão" é uma palavra de origem grega, em que autos significa "si mesmo" e gesto, "gestão", expressando, assim, a "gestão direta e democrática dos trabalhadores nas funções de planificação, direção e execução". Portanto, a autogestão, na visão destes autores, parte do princípio político e filosófico de que "os homens são capazes de se organizarem sem dirigentes". De acordo com Robaquim e Quintaes (1972), a autogestão como modelo de gestão empresarial foi criada na Iugoslávia como forma de contestação ao centralismo burocrático soviético e se caracteriza pela participação direta dos trabalhadores e trabalhadoras no comando da empresa. Almeida (1983) também considera que a autogestão nasceu, como prática, na Iugoslávia de Tito e acabou por se consolidar em teoria.

Singer (2003) afirma que a autogestão de uma empresa solidária difere completamente (ou deveria diferir) da administração de uma empresa capitalista, uma vez que, na primeira, todas as informações relevantes se encontram disponíveis aos interessados de forma transparente, o que reduz os conflitos de interesses seccionais provenientes da disputa entre interesses conflitantes nos diferentes níveis hierárquicos da organização. Tais conflitos de interesse se reduzem porque, na empresa autogestionária, a administração é exercida de maneira democrática, com decisões tomadas coletivamente, seja por assembleias periódicas, constantes nas organizações de pequeno porte, ou por assembleias mais esporádicas ou delegados eleitos entre todos os membros, para as organizações de maior porte (SINGER, 2006). Uma empresa solidária ou empreendimento solidário, para Singer (2006), é aquela organização que se pauta pela Economia Solidária, entendida como "um outro modo de produção, cujos princípios básicos são a propriedade coletiva ou associada do capital e o direito à liberdade individual" (SINGER 2006, p. 10). A Economia Solidária se propõe, portanto, a repensar os vínculos sociais estabelecidos entre as pessoas dentro das organizações, imersas, por sua vez, em um mercado capitalista (CHANIAL e LAVILLE, 2006).

A noção de autogestão proposta por Singer (2006) a coloca não só como característica da Economia Solidária, mas como uma nova forma de organização do trabalho. E, por estar inserida neste contexto da Economia Solidária, conforme acrescenta Liboni (2002), o debate sobre a autogestão como forma de administração das organizações supera a questão do debate sobre se esta prática é ou não uma alternativa ao desemprego para representar a discussão da possibilidade de uma transformação do sistema econômico vigente. Robaquim e Quintaes (1972), por sua vez, não pensam em transformação total, mas afirmam que a autogestão pode ser encarada também como uma forma de aprimoramento do capitalismo.

Conquanto não pensemos a autogestão dessa forma, como instrumento para aprimorar o capitalismo, não podemos negar que as ideias de Robaquim e Quintaes (1972) podem já estar em uso pelo próprio sistema capitalista, que vem adotando formas de participação (ainda que limitadas) dos trabalhadores e trabalhadoras nas empresas e percebendo os resultados econômicos advindos delas. Por essa razão, é oportuno alinhar-se a Gaiger (2006) e Tragtenberg (1989), que ajudam a definir as razões que distinguem a autogestão dessa participação parcial das pessoas dentro das organizações capitalistas: a indivisibilidade entre capital e trabalho e a distinção entre cogestão e autogestão, respectivamente. 
Gaiger (2006) aponta que a principal distinção entre a produção capitalista e a produção sob a forma de autogestão consiste na indivisibilidade entre capital e trabalho, que ocorre no segundo caso. Segundo o autor, tal indivisibilidade acontece pelo fato de que, na autogestão, as pessoas que se apropriam do excedente produtivo são as mesmas que deliberam sobre o destino e finalidade desses recursos: os trabalhadores e trabalhadoras associados. Em outras palavras, no trabalho autogestionário elimina-se a divisão social do trabalho entre trabalhadores, proprietários e gestores, uma vez que todos esses papéis são assumidos pelos próprios trabalhadores e trabalhadoras, ocorrendo, portanto, a vinculação do capital e do trabalho às mesmas pessoas.

Tragtenberg (1989) reforça a distinção existente entre as práticas de autogestão e as de co-gestão, que podem ser encontradas em empresas capitalistas como instrumento disfarçado de controle dos trabalhadores e trabalhadoras. Para Tragtenberg (1989), as relações hierárquicas nas empresas servem como instrumento ideológico para a manutenção do status quo no ambiente empresarial, mediante o discurso da competência do chefe e do caráter "sagrado" de sua liderança.

Contudo, a própria discussão da autogestão é ainda mais complexa do que se imagina. Gutierrez (1988), embora considere que, nas empresas autogestionárias, não devam existir hierarquizações formais ou autoridade burocrática, de modo que todas as pessoas envolvidas nas ações da empresa tenham direito a participar das ações, as quais devem ser consensuais entre todos, admite a existência de autoridades consentidas dentro dessas organizações, em virtude da experiência e do respeito que algumas dessas pessoas podem inspirar nos demais. O autor apresenta, em seu estudo, a possibilidade de a autogestão ocorrer mesmo em empresas, não só em empreendimentos não-capitalistas. Para Gutierrez (1988), a autogestão possui um caráter dúbio: como forma de "anti-gestão", ela emerge, justamente, das contradições da gestão empresarial tradicional.

A visão de Gutierrez (1988) de que a autogestão é um modelo possível de gestão para as empresas se aproxima da noção apresentada por Liboni (2002) de que a autogestão caminha para a possibilidade de um novo sistema econômico. Contudo, como indica Alcântara (2005), a institucionalização da Economia Solidária e, por conseguinte, de seu princípio da autogestão, não se dá meramente por meio da proliferação de empreendimentos solidários, mas pela rotinização e reflexividade da cooperação. Venosa (1982) ressalva que a conscientização das pessoas para a autogestão não deve se pautar pela imposição de uma nova ordem, sob o risco de que isto resulte em um autoritarismo.

Robaquim e Quintaes (1972) apontam duas dificuldades para a aplicabilidade da autogestão como forma de aprimoramento do sistema capitalista. A primeira é a existência do que ele chama de "famílias tecnocráticas", formadas por profissionais da Administração que, embora busquem a eficiência da empresa, fazem-no para ganhar notoriedade, com o objetivo de valorizar suas carreiras. Para os autores, estes profissionais se utilizam de um tecnicismo ligado somente à produtividade e devem ser disciplinados pela existência de conselhos de trabalhadores, para que busquem atender melhor aos interesses legítimos dos trabalhadores e trabalhadoras. Uma questão não abordada pelo autor e que julgamos de importância para essa discussão é a própria formação desses administradores, que aprendem na faculdade a lidar somente com formas hierarquizadas de gestão e, por essa razão, podem ter dificuldades em propor soluções aos problemas das organizações autogestionárias, como Barretos e Paes de Paula (2009) observam.

Outro entrave estaria, segundo Robaquim e Quintaes (1972), na resistência dos trabalhadores e trabalhadoras à participação, em virtude do individualismo e do interesse focado na família, que acabam prevalecendo sobre a "consciência de classe". A esse desinteresse dos trabalhadores e trabalhadoras, os autores somam a possível resistência de líderes sindicais, "que poderiam ver na autogestão uma ameaça à sua influência" (ROBAQUIM e QUINTAES, 1972, p. 97). Desse modo, considerando-se a resistência dos trabalhadores e trabalhadoras, vemos também que a potencialidade e os desafios da autogestão esbarram na questão da subjetividade, que não é apenas individual, mas também coletiva, conforme se verá a seguir. 


\section{A Subjetividade Individual e Coletiva ou as Dificuldades das Transformações Sociais}

De acordo com Domingues (1999), os cientistas sociais, em geral, tomam o conceito de subjetividade apenas em seu sentido individual, tendo como referência um modelo em que as sociedades são reduzidas a seus membros individualmente.

Por outro lado, Calderón $(2008$, p. 2) alerta para o fato de que outras abordagens correntes da subjetividade têm produzido "resultados paradoxais", carregados sobremaneira de determinismos que acabam por produzir uma visão em que homens e mulheres aparecem reduzidos a meros "marionetes sem profundidade psicológica e sem liberdade".

Assim, Elias (1994) apresenta a necessidade de se pensar na subjetividade em um sentido não só individual, mas também mais amplo, coletivo, ao observar que as sociedades são mais que a mera adição de seus indivíduos, tomados separadamente. Para este autor, tanto a sociedade quanto os indivíduos só existem um em relação ao outro (ELIAS, 1994).

Para Elias (1994), todas as pessoas que compõem uma sociedade estão presas umas às outras por meio de uma "cadeia de atos", em que cada pessoa, ao desempenhar dada função dentro da sociedade, passa a se relacionar com outras pessoas que desempenham outras funções, ainda que não perceba, em uma relação de interdependência.

As pessoas, quando nascem, chegam a um mundo que já estabeleceu história anterior a elas, de modo que cada indivíduo se transforma, desde quando nasce, em um ser complexo, ao longo de sua vida, mediante seu relacionamento dentro da sociedade, ao mesmo tempo em que já chega ao mundo individualizado por suas constituições naturais. Contudo, cada pessoa se desenvolve individualmente, independente dessa constituição característica, o que dá margem a uma vasta gama de individualidades possíveis (ELIAS, 1994).

Tanto Elias (1994) quanto Domingues (1999) concordam que apenas analiticamente é possível a separação entre as partes e o todo. Lefebvre (1969 apud DOMINGUES, 1999) trata da noção de causalidade coletiva, segundo a qual não é possível inferir relações de causa e efeito dos fenômenos, uma vez que as coisas são causas umas das outras reciprocamente. Lefebvre (1969 apud DOMINGUES, 1999) ilustra a causalidade coletiva com o exemplo da margem da praia, que representa a área de contato entre o mar e o continente e é, ao mesmo tempo, o local onde um finda e o outro inicia, resultando na margem. Assim, a ideia de causalidade deve levar sempre em consideração as noções de proximidade e importância relativas.

Desse modo, não se trata de separar ou de sobrepor em importância indivíduo ou sociedade, mas de se pensar que um influencia o outro, reciprocamente, tal como sugere a noção de causalidade coletiva (ELIAS, 1994; DOMINGUES, 1999). Afinal, a margem é onde inicia o continente ou onde termina o mar? Para os autores, seria ambos, tal como a subjetividade é, ao mesmo tempo, individual e coletiva.

Embora considere que a causalidade coletiva possa existir não só em sistemas sociais humanos, mas também nos sistemas naturais, Domingues (1999) coloca a subjetividade como uma exclusividade humana, uma vez que esta implica a reflexividade. Ainda que animais, por exemplo, possam esboçar estados emocionais por meio de gestos e ações, o comportamento que demonstram não apresenta significado a eles, tal como ocorre com as pessoas. Portanto, apenas as pessoas desenvolvem, efetivamente, a subjetividade (DOMINGUES, 1999).

Essa subjetividade, conforme exposto, é tanto coletiva quanto individual. As subjetividades coletivas exercem sua causalidade coletiva em relação a outras subjetividades coletivas sem que haja, necessariamente, uma direção precisa ou uma intencionalidade coletiva sobre o impacto causal, pois as pessoas que a integram podem agir de tal forma que ocorra, como resultado final, uma "total dispersão da eficiência da coletividade" (DOMINGUES, 1999, p. 28). 
No entanto, Domingues (1999, p. 28) afirma que, mesmo quando há uma intenção inicial clara das coletividades e as pessoas se proponham a atingi-las de forma ordenada, podem ocorrer resultados inesperados, como "consequências não-intencionais" da ação. Isso porque, como Domingues (1999) e Elias (1994) mostram, os indivíduos e a sociedade são indissociáveis e se influenciam mutuamente.

Corroborando a questão da subjetividade coletiva, Elias (1994) aponta que há equívocos nas abordagens que privilegiam apenas a agência ou a estrutura. Para este autor, no primeiro caso, os indivíduos são tidos como "postes sólidos entre os quais, posteriormente, se pendura o fio dos relacionamentos", enquanto, no segundo, a sociedade é vista como algo de existência anterior e independente em relação às pessoas (ELIAS, 1994, p. 25).

Segundo Elias (1994), cada pessoa carrega, em si, a marca da sociedade. Desse modo, a subjetividade das pessoas não pode se dissociar das esferas individual e social. Com isso, argumenta-se que as pessoas trazem consigo, em suas subjetividades, marcas como as da naturalização das hierarquias, apreendidas mediante o processo de socialização a que todos estamos submetidos desde o momento em que nascemos.

McCabe (2007) reforça essa visão ao apontar que o pensamento dualístico entre agência e estrutura, individual e coletivo, dentro da questão da subjetividade, acaba por empobrecer a compreensão acerca dos processos de trabalho e do próprio mundo social em que vivemos. Por conseguinte, McCabe (2007, p. 4) entende que a subjetividade consiste no "resultado auge de várias relações de poder e as interpretações, reflexividade e ações recíprocas de um indivíduo a qualquer momento".

Em outras palavras, o autor entende a subjetividade como o modo pelo qual as pessoas conferem significado a si mesmas e ao mundo que as cerca, considerando que a subjetividade é mediada pelas múltiplas experiências que se refletem nestes significados, tais como "política, classe, gênero, etnia, comunidade, nacionalidade, religião, família, colegas e grupos de trabalho, comércio e/ou sindicalismo, que dão origem a significados, sentimentos e afiliações" (McCABE, 2007, p. 4).

Desse modo, mesmo trabalhando em um empreendimento de Economia Solidária, os trabalhadores e trabalhadoras continuam a viver em um mundo capitalista, ocorrendo, portanto, um grande choque de culturas (LOURENÇO, 2008). Nesse sentido, como observa esta mesma autora, a autogestão passa a ser percebida pelos trabalhadores e trabalhadoras como uma nova concepção de trabalho. A dificuldade que os empreendimentos solidários têm para alcançar a autogestão é abordada por Castanheira e Pereira (2008, p. 117), que afirmam: "[...] tanto a economia solidária quanto a autogestão envolvem proposições que rompem com os pressupostos capitalistas, exigindo a adoção de novos conceitos e valores que não se sustentam somente por artifícios econômicos".

Com isso, os autores apresentam a dificuldade que os membros de empreendimentos solidários têm não só para obter sua renda (de suma importância para estes grupos, visto que a maioria é composta por trabalhadores e trabalhadoras em situação de exclusão econômica e precarização do trabalho), mas também para dar sentido a essa nova forma de trabalho diante do predomínio de valores como a eficiência econômica e a competição, presentes na realidade em que estão imersos, e também para se alinharem aos pressupostos da Economia Solidária, que implicam uma reversão dos valores capitalistas a que estão expostos.

Lourenço (2008) e Gaiger (2004) corroboram esta visão ao afirmarem que a Economia Solidária dá origem a novas formas de subjetividade, as quais configuram novas visões sobre o contexto do trabalho, que, por sua vez, se entrelaçam com as experiências preexistentes das pessoas, exigindo, assim, novas construções subjetivas. Por essa razão, a autogestão figura entre os grandes desafios para a formação de empreendimentos vinculados à Economia Solidária, em razão de exigir dos trabalhadores e trabalhadoras essa transformação de suas subjetividades (LOURENÇO, 2008; GAIGER, 2004). 
Se pensarmos na subjetividade como mais do que algo meramente individual, mas coletivo, como, então, realizar as mudanças sociais que poderiam impactar essa subjetividade coletiva? Tendo como base a questão do conservadorismo como ideologia moderna, Wallerstein (2003) faz uma análise de experiências da história e do presente para traçar suas sugestões de rumo para uma nova sociedade. $\mathrm{O}$ autor mostra que mesmo movimentos como a Revolução Francesa e a Revolução Russa não constituíram "revoluções" plenas, visto que não implicaram uma mudança no modo de funcionar dos Estados em que se realizaram, nem na estrutura de sustentação desse funcionamento. Contudo, o autor reconhece a importância desses movimentos pela mudança significativa de "parâmetros importantes sobre como o sistema mundial como um todo vem evoluindo" (WALLERSTEIN, 2003, p.18).

Com base nas considerações acerca das revoluções, Wallerstein (2003) mostra que as mudanças necessárias para a formação de uma sociedade substantiva não virão, certamente, como iniciativas das classes mais privilegiadas. Porém, ainda que as tentativas de insurreições populares tenham "fracassado" no passado, o autor aponta que essas tentativas de mudança social são importantes também como forma de os indivíduos desprivilegiados da sociedade se posicionarem como "atores importantes no sistema mundial"(WALLERSTEIN 2003, p. 22).

Transportando estas observações de Wallerstein (2003) para nosso estudo, vemos que, embora os princípios da Economia Solidária (entre os quais se encontra a autogestão) possam não ser plenamente professados pelos trabalhadores e trabalhadoras que se propõem a implantar a autogestão em suas organizações, a própria iniciativa destes de se organizarem mediante uma empresa de autogestão já é uma forma de exercício de contrapoder dentro do sistema mundial e um modo de se colocarem como "atores importantes" (WALLERSTEIN, 2003).

A dificuldade de aplicação efetiva das transformações sociais, no decorrer da História, como observa Wallerstein (2003) remete-nos à causalidade coletiva e às "consequências não-intencionais" da ação humana que, aliadas à própria noção de subjetividade, entendida não como meramente individual, mas também coletiva, podem trazer novas reflexões acerca dos desafios à implantação e sobrevivência de empreendimentos autogestionários na sociedade. Elias (1994) e Domingues (1999) mostram que, mesmo coletividades que se proponham a trabalhar de maneira autogestionária, em forma de cooperativas, associações ou empresas, podem sofrer "consequências não-intencionais" de suas ações. Isso implica que, mesmo dentro de um empreendimento solidário em que todas as pessoas tenham objetivos convergentes, não é possível determinar os resultados de suas ações.

Feitas as devidas considerações, apresenta-se, a seguir, o caminho metodológico adotado nas discussões acerca dos desafios para a prática da autogestão, com base nos relatos dos especialistas entrevistados.

\section{Metodologia}

A fim de compreender os desafios da autogestão na percepção de especialistas da área, buscou-se organizações que tivessem trabalhos de fomento a empreendimentos de Economia Solidária. Chegou-se, por meio de processo de julgamento, a quatro organizações: ADS Agência de Desenvolvimento Solidário (ADS), ANTEAG, UNISOL e UNITRABALHO. Foi feito contato por meio de correio eletrônico e ligações telefônicas, solicitando que cada organização destacasse uma pessoa que pudesse tratar do tema da autogestão. Cada organização indicou um especialista no assunto, com exceção da ADS, que, em virtude de sua agenda, não pôde dispor de seu tempo. Os contatos foram realizados entre outubro de 2009 e janeiro de 2010 .

Para a coleta dos dados, foi utilizado o método de entrevista semi-estruturada. As entrevistas foram realizadas na mesma época da realização dos contatos e aconteceram nos escritórios da ANTEAG e da 
UNITRABALHO, em São Paulo/SP, e no escritório da UNISOL, em São Bernardo do Campo/SP. A entrevista pode ser entendida como a técnica que envolve duas pessoas numa situação "face a face" e em que uma delas formula questões e a outra responde (GIL, 2002, p. 114). Já para Haguette (1987), é vista como um processo de interação social entre duas pessoas, na qual o entrevistador busca obter dados por parte do entrevistado. Quando se aplica a entrevista semi-estruturada, segue-se um roteiro, que pode ser reformulado e acrescido no decorrer da própria entrevista, como ocorreu em nesta pesquisa (ALENCAR, 2000).

Cotanda et al (2008) definem que, na entrevista semi-estruturada, não existem perguntas pontuais, mas dimensões que demandam do respondente uma resposta mais narrativa. Assim, embora o pesquisador discrimine em seu roteiro os aspectos principais na entrevista, esta transcorre livremente, com a abordagem dos tópicos sugeridos pelo cientista. Os dados obtidos por meio das entrevistas foram analisados utilizandose a técnica de análise de conteúdo, definida por Campos (2004) como um conjunto de ferramentas que possibilita a análise de dados qualitativos de pesquisas.

$\mathrm{Na}$ análise de conteúdo, segundo Rocha e Deusdara (2005, p. 307), busca-se "alcançar uma pretensa significação profunda, um sentido estável, conferido pelo locutor no próprio ato de produção do texto". Para estes autores, a análise de conteúdo, mediante interpretação dos relatos, se propõe a ir além das "superfícies" do texto, buscando revelar os elementos ideológicos e subjetivos que se encontram escondidos nas narrativas (ROCHA e DEUSDARA, 2005).

De acordo com Campos (2004), uma vez transcritos os dados de entrevistas, passa-se à primeira etapa da análise de conteúdo, a leitura flutuante. Esta etapa consiste numa primeira leitura do material, a fim de que o pesquisador tenha suas primeiras impressões sobre os dados. Feito isso, o pesquisador deve realizar outras leituras desse material, a fim de identificar as ideias gerais ali presentes.

O próximo passo, ainda para Campos (2004), é a seleção das unidades de análise, os principais temas que são escolhidos conforme os objetivos de estudo, o referencial teórico adotado, ou, até mesmo, com base em teorias intuitivas do próprio pesquisador (CAMPOS, 2004). O último passo, para Campos (2004), é a categorização, a separação dos temas em grandes enunciados denominados categorias, de acordo com seu grau de proximidade, podendo ser apriorísticas ou não apriorísticas. As categorias apriorísticas são predeterminadas pelo pesquisador com base em sua experiência prévia ou interesse de pesquisa, enquanto a categorização não apriorística ocorre quando as categorias emergem dos próprios relatos obtidos com a pesquisa. Neste estudo, destacam-se como categorias o conceito de autogestão e os principais desafios para sua implantação nas organizações, de acordo com os entrevistados, utilizando-se, portanto, categorização apriorística. Uma vez realizadas essas etapas, os relatos, sejam oriundos de documentos ou entrevistas, são sistematizados e organizados, facilitando a análise dos dados frente às teorias adotadas para o estudo (CAMPOS, 2004). Tais análises encontram-se no item a seguir.

\section{Os Desafios da Autogestão na Percepção de Especialistas da ANTEAG, UNISOL e UNITRABALHO}

As organizações que, gentilmente, nos receberam e indicaram profissionais que pudessem nos relatar os desafios da autogestão em sua percepção têm trajetórias um pouco distintas, mas foram escolhidas para integrar este estudo por apoiarem empreendimentos de Economia Solidária, seja por meio da criação de novos empreendimentos ou pela assessoria a organizações já existentes, nas mais diversas atividades econômicas.

A ANTEAG, de acordo com o relato da pessoa entrevistada, surgiu em meados da década de 1990, em virtude de uma demanda de empresas que começaram a entrar em falência com a abertura econômica promovida pelo governo Collor e procuraram apoio junto a técnicos do DIEESE (Departamento Intersindical de Estatísticas e Estudos Socioeconômicos). A UNISOL, por sua vez, surgiu também de uma demanda de 
trabalhadores e trabalhadoras de empresas que vieram à falência, nesse mesmo contexto histórico, e que buscaram apoio junto ao Sindicato dos Metalúrgicos do ABC Paulista, mas foi formalizada, também sob a forma jurídica de associação apenas em 2004. Tanto a ANTEAG quanto a UNISOL, além de realizarem trabalhos de fomento e assessoria a empreendimentos solidários, são entidades de representação dos trabalhadores e trabalhadoras e das organizações por eles compostas. A UNITRABALHO, por sua vez, se distingue das demais por não possuir caráter de representação, mas de fomento da Economia Solidária via suas incubadoras de empreendimentos solidários e realização de estudos. Caracteriza-se juridicamente como uma fundação, prestando apoio às universidades que compõem sua rede para a realização de estudos e pesquisas sobre o trabalho. Assim, a UNITRABALHO distingue-se também das demais por não lidar exclusivamente com a temática da Economia Solidária.

As pessoas entrevistadas serão tratadas aqui como Especialistas (Esp.) número 01, 02 ou 03, conforme a ordem cronológica em que se deram suas entrevistas. Não se fará menção aqui à organização a que pertence cada pessoa entrevistada em virtude de que, como elas apresentaram sua percepção pessoal acerca da autogestão e seus desafios, suas opiniões podem não refletir, necessariamente, a visão de suas organizações como um todo.

Por esta razão, a fim de preservar a identidade das pessoas entrevistadas, evitou-se identificá-las com sua respectiva organização, omitindo-se suas profissões, que poderiam revelar a que entidade cada especialista pertence. Esp. 01 e Esp. 02 possuem características semelhantes: ambas são mulheres e tiveram uma trajetória de militância na Economia Solidária anterior ao ingresso em suas respectivas organizações de fomento da Economia Solidária. Esp. 01 trabalha em sua entidade desde 2002, como assessora, e Esp. 02 atua desde 2009, em sua organização, como assessora técnica. Já Esp. 03 é um homem, que afirmou atuar em sua organização há cerca de dezoito anos. Chegou a ocupar a direção de sua entidade e, atualmente, trabalha assessorando projetos. Teve seu primeiro contato com a Economia Solidária ao trabalhar na entidade a que pertence, que, segundo seu relato, foi uma das pioneiras na discussão da Economia Solidária no Brasil.

Ao serem indagados sobre como enxergam os desafios da autogestão, os especialistas entrevistados acabavam por demonstrar o que entendem por autogestão, como mostra o relato de Esp. 03:

Particularmente, como eu falei, não sou especialista na área, a autogestão é um horizonte, é como se fosse uma utopia a ser buscada e que, na prática, você vai tentando se aproximar da autogestão. A autogestão seria, no caso de uma empresa, os trabalhadores sendo os próprios gestores da empresa, em todos os sentidos, seria que eles tomariam todas as decisões importantes e necessárias para o funcionamento da empresa. No caso de uma instituição, o mesmo caso se aplica: quem trabalha toma todas as decisões dentro da instituição. Então, essa seria a ideia da autogestão. Porém, a gente sabe que é praticamente impossível, na prática, que isso aconteça. Por isso que eu digo que é algo a ser buscado. Na realidade, você tem sempre que lidar com relações de poder, com relações de hierarquia, que são, numa certa medida, necessárias também para o trabalho funcionar. Então, eu acho que uma autogestão perfeita, completa, nunca vai existir e, se existisse, talvez ela não fosse viável na prática. Então, na prática, eu acho que o que funciona é um certo grau de autogestão naquilo que é mais importante, então, as decisões que são mais importantes têm que ser tomadas, realmente, coletivamente pelas pessoas que trabalham e as questões mais técnicas, as questões que não são tão decisivas para o empreendimento têm que ser delegadas para quem tem capacidade de decidir, para quem tem capacidade de organizar o trabalho da melhor forma possível. Eu acho que o grande desafio da autogestão é a questão de conciliar a viabilidade econômica com a democracia do empreendimento. Ou seja, é você garantir que as pessoas participem das decisões sem que isso atrapalhe o funcionamento eficiente de uma cooperativa ou de uma empresa recuperada que tem que ter agilidade, tem que ter capacidade de competir em uma sociedade. (Esp. 03) 
Esp. 03, apesar de deter uma longa trajetória em sua organização, modestamente, não se considerou "especialista" em autogestão. Sua visão sobre o tema se aproxima da noção do conceito como uma forma de gestão não hierárquica e democrática, exposta por autores como Gutierrez (1988), Singer (2006) e Liboni (2002). Contudo, ele considera que a autogestão plena, na prática, seria uma "utopia", um horizonte inalcançável, e coloca como desafio à autogestão a questão da viabilidade econômica do empreendimento solidário, que poderia, em sua visão, ser prejudicada pela tomada de decisão coletiva em "questões mais técnicas", as quais deveriam ser responsabilidade de "quem tem capacidade de organizar o trabalho da melhor forma possível". Esp. 03 demonstra, portanto, em seu relato, concordar com a crítica à emergência de formas democráticas de gestão com base no argumento econômico, ao qual se contrapõe Johnson (2006), e também com a necessidade de que certas decisões sejam tomadas por especialistas em gestão, por exemplo, que tenham tal capacidade de organização do trabalho. A visão da autogestão como "utopia", entretanto, pode revelar também que Esp. 03 a enxerga, tal como Liboni (2002), como uma forma de transformação do sistema econômico vigente, daí suas dúvidas sobre a concretude de uma autogestão plena.

Esp. 01 e Esp. 02, por outro lado, enxergam a autogestão como forma de gestão organizacional, a exemplo de Robaquim e Quintaes (1972), Tragtenberg (1989), Singer (2003), Gaiger (2006), Lechat e Barcelos (2008), que a conceituam como uma forma democrática de administração. Ambos demonstram também um alinhamento com a ideia de Chanial e Laville (2002) de que a Economia Solidária é uma forma de economia plural, que visa a rever vínculos sociais dentro de empreendimentos que, por sua vez, estão imersos em um mercado em que prevalecem valores capitalistas, como exemplifica a seguinte fala de Esp. 01:

Como é que eu sou autogestionário, como é que eu lido com a Economia Solidária se eu tenho que lidar dentro de um sistema capitalista? Então, quem vai comprar, assim, usando novamente o exemplo da garrafa d'água, quem vai comprar essa água não quer saber se eu me reúno em grupo, se eu faço... eu quero a melhor qualidade de água, eu quero a melhor apresentação, eu quero o melhor preço. Então, você tem que concorrer dentro de um mercado capitalista sem perder os seus conceitos autogestionários. Isso é muito difícil. (Esp. 01)

Neste excerto, fica implícita a visão de que o mercado capitalista, em que se inserem os empreendimentos solidários, concorre em valores com o princípio da autogestão. Nele fica clara a noção de que a estrutura influencia na subjetividade coletiva. Desse modo, os clientes dos empreendimentos solidários, alheios aos valores autogestionários da empresa, procuram a satisfação de seus interesses de consumo, evidenciados pela busca de boa qualidade aliada a baixos preços, tal como preconiza a instrumentalidade do capital, sem se importarem com o as especificidades do modo de produção de tais empreendimentos, quais sejam, mais justo e fraterno. A noção de subjetividade coletiva e, ao mesmo tempo, individual, proposta por Elias (1994) e Domingues (1999), está presente no trecho em que Esp. 01 comenta que, apesar da influência da subjetividade coletiva da sociedade, que cobra por produtos/serviços que satisfaçam às exigências do mercado capitalista, ainda que com dificuldade, os empreendimentos solidários podem tentar não perder seus ideais autogestionários, o que significa que eles não são agentes passivos dentro do mercado, ainda que se vejam na obrigação de atendê-lo.

Em razão dessa visão da Economia Solidária como economia plural (CHANIAL e LAVILLE, 2006), Esp. 01 e Esp. 02 colocam como principal desafio à autogestão a necessidade de transformação da subjetividade dos trabalhadores e trabalhadoras que se propõem a trabalhar mediante essa forma de gestão, como apontam Lourenço (2008) e Castanheira e Pereira (2008), já que a Economia Solidária preconiza valores distintos dos que predominam na sociedade, os quais são eminentemente capitalistas:

Nós somos criados dentro de um sistema altamente capitalista, altamente individualizado, onde você tem que ser, não é de individuação em si, mas é de individualização, onde você tem que ser o melhor. E, aí, você chega com uma proposta de coletividade, você já bate 
num primeiro desafio, que é desconstruir uma ideia de que tem que ter uma competição aqui dentro. Então, muitas vezes, o próprio trabalhador, ele quer ter o ganha-pão dele, mas isso não quer dizer que ele quer se relacionar com um, com as pessoas que estão ali, sabe? Existe uma coisa da própria comodidade de que assim 'ah, eu tenho um chefe, joga o problema pra ele'. E aí, quando o problema é nosso, não é mais só do chefe? Por outro lado, a gente percebe uma coisa no seguinte sentido. É 'olha, eu vou, eu faço isso, eu sou cooperado, então tudo o que tem aqui é meu'. 'Então, vou levar isso porque isso é meu'. Mas não é meu, é nosso. Essa distinção, essa... reconstrução, na verdade, porque é mais que desconstrução, a reconstrução a partir dos valores que ele tem, você só consegue a partir do próprio saber dele. $\mathrm{O}$ que ele acumulou. Primeiro que ele tem uma coisa de se sentir mesmo incapaz dentro do processo, sempre falaram pra ele que o administrativo, a pessoa que cuidava das contas, a pessoa que fazia. A primeira tentativa sempre era a de querer contratar uma pessoa de fora e as nossas experiências sempre mostraram que esse nunca foi o melhor caminho. Assim, o que a gente percebe é que tem muita dificuldade em relação a isso, porque, aí, principalmente quando vem alguém de fora, aí, então, eles deixam chegar naquele... então, uma das conversas que a gente tem é essa coisa de que se chegou num processo falimentar foram essas pessoas que estavam lá. (Esp. 01, grifo nosso)

Às vezes, a gente quer construir algo coletivo, só que vem de uma cultura individualista. E a gente, internamente, não consegue fazer ações coletivas no seu dia a dia. E aí, você consegue estar dentro de uma instituição, no seu trabalho, em que você 'aperta uma chavezinha' ali e muda e, daí em diante, você consegue, a partir daquele horário, das oito às seis, construir coletivamente? Se nos seus atos, no dia a dia, você não faz isso? Então, como você casa isso? Entendeu? Se a gente está mudando um paradigma, porque a Economia Solidária quer mudar um paradigma, ela quer mudar uma relação social. Se ela tem esse princípio, ela não pode só acontecer dentro das relações de trabalho. Tem que estar sendo construída nas relações do dia a dia. Porque, senão, é um contrassenso. Nós somos humanos, não somos máquinas que conseguimos mudar, uma hora é 110 e outra hora é 220, entendeu? (Esp. 02)

A ideia de "reconstrução", citada por Esp. 01, reforça a necessidade de transformação da subjetividade como fator necessário à autogestão, conforme comentamos anteriormente. Para Esp. 01, a superação do individualismo preconizado pelo sistema capitalista e o fato de os trabalhadores e trabalhadoras estarem acostumados, dentro do regime do trabalho hierarquizado, a apenas obedecerem, sem participação nas decisões nem responsabilidade pelos resultados dessas decisões, levam estas pessoas a enxergarem a heterogestão como a única forma possível de organização do trabalho, sem que percebam a possibilidade do trabalho coletivo e democrático dentro da autogestão. A cultura individualista é apontada também por Esp. 02 como um desafio a ser superado pelas pessoas que se propõem a trabalhar de forma autogestionária. A imagem da "chavezinha" que liga ou desliga a capacidade de as pessoas agirem de forma altruísta, aos moldes autogestionários, remete à noção de Alcântara (2005) de institucionalização da Economia Solidária na sociedade, uma vez que Esp. 02 explica que, em sua visão, não há como as pessoas se despirem da subjetividade coletiva, impregnada dos valores capitalistas, só porque se dispuseram a trabalhar de forma autogestionária, pois esta subjetividade coletiva também se expressa em suas subjetividades individuais e vice-versa, tal como apresentam Elias (1994) e Domingues (1999). Assim, a institucionalização da Economia Solidária, a rotinização e a proliferação da cooperação na sociedade implicariam transformação de uma subjetividade coletiva individualista em solidária, pois as pessoas são, como mostram Elias (1994) e Domingues (1999), produto e produtoras da sociedade em que vivem, não "máquinas" que conseguem se desligar da subjetividade coletiva ao seu redor dentro do empreendimento solidário para ligarem-se a ela, ao deixarem seu ambiente de trabalho. 
Esp. 01, ao mencionar "essas pessoas", ou seja, os gestores da empresa falida, como responsáveis pelo fim das suas atividades econômicas mediante administração aos moldes capitalistas, se contrapõe à ideia de Esp. 03 de que certas decisões técnicas deveriam ficar a cargo de especialistas, como administradores. Não se trata de um questionamento da capacidade ou da importância do papel dos profissionais em Administração, uma vez que as três organizações de fomento oferecem formação não só em Economia Solidária, mas também em gestão aos empreendimentos que assessoram ou ajudam a fundar.

Contudo, as técnicas e ferramentas da Administração são adaptadas por estas organizações para que possam atender às características dos empreendimentos solidários, cuja finalidade se pauta não só nos resultados econômicos, mas sociais. Assim, como aponta Gaulejac (2007), a gestão é necessária e benéfica à sociedade, contanto que não prime apenas pela questão essencialmente econômica (DEJOURS, 2007). A fala de Esp. 01 contrapõe-se à de Esp. 03 no sentido de que trabalhadores e trabalhadoras têm capacidade de utilizar de maneira aperfeiçoada os saberes administrativos, eliminando a cisão entre planejamento e execução do trabalho, que o discurso de Esp. 03 parece reforçar ao mencionar a necessidade de pessoas habilitadas, ou seja, educadas dentro da "educação legítima” em Administração, o que Aktouf (2004) critica.

\section{Considerações Finais}

As diferentes percepções dos especialistas acerca dos desafios à prática da autogestão mostram que, mesmo para pessoas que se dedicam diariamente a fomentar a criação de novos empreendimentos solidários ou a prestar assessoria a organizações desse tipo, a autogestão ainda gera incertezas, uma vez que parece caminhar na contramão do que preconiza a teoria administrativa corrente. Essas incertezas quanto à aplicação da autogestão plena na prática se refletem em seu campo teórico, que a coloca ora como instrumento de modificação social, ora como aprimoramento do sistema vigente, nova concepção de trabalho ou, ainda, como nova forma de gestão.

Colaborando para esta discussão, Gaiger (2006) afirma que, embora os estudos sobre autogestão tenham crescido nos últimos tempos, ainda são raros os estudos empíricos que enfoquem as questões internas dos empreendimentos. Na visão do autor, a área carece de estudos que se dediquem a analisar internamente os empreendimentos solidários no decorrer de sua história, atentando para aspectos da vida cultural, material e social que impulsionaram as pessoas a aderirem e, sobretudo, a permanecerem trabalhando sob a forma de autogestão.

Assim, Gaiger (2006) observa que os estudos da área têm enfocado somente as circunstâncias que, à revelia e contragosto dessas pessoas, forçaram-nas a ingressar em uma organização autogestionária, em uma situação de trabalho nova para a grande maioria desses trabalhadores, como se tais pessoas tivessem adotado postura passiva nesse processo. Essa primazia nas rupturas em lugar de uma busca pelo entendimento de processos e permanências por parte dos pesquisadores da área nos remete à percepção que Esp. 03 tem da autogestão como "utopia", pois é assim que, segundo Gaiger (2006), o meio acadêmico parece tratar o tema. Se não encontra, na prática, uma organização que atenda a todos os requisitos daquilo que a academia entende por autogestão, simplesmente considera que empresas autogestionárias não existem.

Isso significa que as pessoas que têm estudado as organizações autogestionárias têm deixado de pensar nos importantes processos que os trabalhadores e trabalhadoras desses empreendimentos têm realizado no sentido da superação de um preconceito que a própria área da Administração ajuda a fomentar: a ideia de que existem pessoas aptas a pensar e decidir dentro das organizações e outras que só são capazes de executar metodicamente trabalhos não intelectuais. Afinal, se as empresas se transformaram em cenários da "inculcação ideológica", como afirmou Tragtenberg (1989, p. 25), a Teoria Administrativa corrente e os profissionais formados por ela têm sua participação nessa situação. Talvez, então, a resolução de alguns 
problemas mais próximos, como mostra Wallerstein (2003), esteja sob nossa responsabilidade, mais que imaginamos.

Por essas razões, este estudo pode colaborar para estudos posteriores sobre as organizações autogestionárias por promover a discussão de aspectos internos a esse tipo de organização, tal como propõe Gaiger (2006), uma vez que a noção de subjetividade individual e coletiva, que encontra apoio teórico em Domingues (1999) e Elias (1994), pode ajudar a revelar as motivações que levam as pessoas a aderirem e permanecerem trabalhando sob uma forma de trabalho que segue uma lógica que entra em choque com os valores sociais vigentes. A subjetividade coletiva pode, ainda, abrir novos olhares sobre a dificuldade de implantação da autogestão na prática dessas organizações, desviando a "culpa" das pessoas ou do "sistema", mas propondo uma discussão mais profunda, que integre ambas as esferas: individual e coletiva.

\section{Referências}

AKTOUF, O. Pós-globalização, administração e racionalidade econômica: a síndrome do avestruz. São Paulo: Atlas, 2004.

ALBORNOZ, S. O que é trabalho. 5. ed. São Paulo: Brasiliense, 1992. 103p.

ALCÂNTARA, F. H. C. Economia Solidária: o dilema da institucionalização. São Paulo: Arte e Ciência, 2005. 170p.

ALENCAR, E. Introdução à metodologia de pesquisa social. Lavras: UFLA/FAEPE, 2000.

ALMEIDA, H. M. M. de. Autogestão: da idéia às práticas. Revista de Administração de Empresas, v. 23, n.1, p. 37$57,1983$.

BARKER, J. A. O exemplo Mondragon. In: HESSELBEIN, F. et al. A organização do futuro: como preparar hoje as empresas de amanhã. São Paulo: Futura, 1997.

BARRETO, R. D. O.; PAES DE PAULA, A. P. Os dilemas da economia solidária: um estudo acerca da dificuldade de inserção dos indivíduos na lógica cooperativista. Cad. EBAPE.BR, v. 7, n. 2, p. 199-213, 2009.

CALDERÓN, J. A. Trabajo, subjetividad y cambio social: rastreando el trabajo emocional de las teleoperadoras. Cuadernos de Relaciones Laborales, v.26, n.2, p. 91-119, 2008.

CAMPOS, C. J. G. Método de análise de conteúdo: ferramenta para a análise de dados qualitativos no campo da saúde. Rev. Bras. Enferm., Brasília, v. 57, n. 5, out. 2004.

CASTANHEIRA, M. E. M.; PEREIRA, J. R. Ação coletiva no âmbito da economia solidária e da autogestão. Revista Katálysis, v. 11, p. 116-122, 2008.

CHANIAL, P.; LAVILLE, J. A economia social e solidária na França. In: FRANÇA FILHO, G. C. et al. (Org.) Ação pública e economia solidária: uma perspectiva internacional. 1. ed. Porto Alegre: Editora da UFRGS, 2006. 326p.

CHILD, J.; MCGRATH, R. G. Organizations unfettered: organizational form in a information-intensive economy, Academy of Management Journal, v. 44, n. 8, p. 1135-1148, 2001.

COSTA, L. A. et al. Estriagem e alisamento: usinando uma autogestão na fábrica. Fractal: Revista de Psicologia, v. 20, p. $447-459,2008$.

COTANDA, F. C. et al. Processo de pesquisa nas ciências sociais: uma introdução. In: PINTO, C. R. J.; GUAZZELLI, C. A. B. (Org.). Ciências Humanas: pesquisa e método. 1. ed. Porto Alegre: Editora da UFRGS, 2008. 148p. (Série Graduação). 
DAL MAGRO, M. L. P.; COUTINHO, M. C. Os sentidos do trabalho para sujeitos inseridos em "empreendimentos solidários". Psicologia em Estudo, v. 13, p. 703-711, 2008.

DEJOURS, C. A banalização da injustiça social. Rio de Janeiro: Editora FGV, 2007.

DELLAGNELO, E. L.; MACHADO-DA-SILVA, C. L. Literatura sobre novas formas organizacionais: onde se encontram as evidências empíricas de ruptura com o modelo burocrático das organizações? In: ENCONTRO NACIONAL DA ASSOCIAÇÃO NACIONAL DOS PROGRAMAS DE PÓS-GRADUAÇÃO EM ADMINISTRAÇÃO, 24., 2000, Florianópolis. Anais... Florianópolis: ANPAD, 2000. p.1-15.

DOMINGUES, J. M. Criatividade social, subjetividade coletiva e modernidade brasileira contemporânea. Rio de Janeiro: Contra Capa Livraria, 1999. 268p.

ELIAS, N. A sociedade de indivíduos. Rio de Janeiro: Jorge Zahar Ed., 1994. 201p.

GAIGER, L. I. Sentidos e experiências da economia solidária no Brasil. 1. ed. Porto Alegre: Editora da UFRGS, 2004. 417p.

. A racionalidade dos formatos produtivos autogestionários. Sociedade e Estado, v. 21, p. 513-545, 2006.

GAULEJAC, V. de. Gestão como doença social: ideologia, poder gerencialista e fragmentação social. Aparecida: Idéias e Letras, 2007.

GIL, A. C. Como elaborar projetos de pesquisa. 4. ed. São Paulo: Atlas, 2002.

GOMIDE, D. Kibutzim: uma visão brasileira do modelo israelense de cooperativa integral. In: SOUZA, A. et al. Uma outra economia é possível: Paul Singer e a Economia Solidária. São Paulo: Contexto, 2003.

GUTIERREZ, G. L. Autogestão de empresas: considerações acerca de um modelo possível. Revista de Administração de Empresas, v. 28, n. 2, p. 7-19, 1988.

HAGUETTE, T.M.F. Metodologias qualitativas na sociologia. Petrópolis: Vozes, 1987. 163p.

HARVEY, D. Condição pós-moderna. 7. ed. São Paulo: Loyola, 1998. 349p.

JOHNSON, P. Whence democracy? A review and critique of the conceptual dimensions and implications of the business case for organizational democracy. Organization, v. 13, n. 2, p. 245-274, 2006.

LECHAT, N. M. P.; BARCELOS, E. D. S. Autogestão: desafios políticos e metodológicos na incubação de empreendimentos econômicos solidários. Revista Katálysis, v. 11, p. 96-104, 2008.

LIBONI, M. T. L. A empresa de autogestão: uma visão psicossocial. 2002. Dissertação (Mestrado), Universidade Estadual de Maringá, Maringá, 2002. 126p.

LOURENÇO, M. L. Cooperativismo e subjetividade: um estudo das dimensões da autogestão, do tempo e da cultura solidária. Curitiba: Juruá, 2008. 94p.

MACKE, J. Organização do trabalho e inovações sistêmicas: um panorama histórico das mudanças na natureza do conhecimento. Revista Eletrônica de Administração, v. 11, n. 4, jul./ago. 2005. p. 1-19.

MCCABE, D. Individualization at work? Subjectivity, teamworking and anti-unionism. Organization, v. 14, n. 2, p. 243-266, Mar. 2007.

MEDEIROS. P. H. R. Do modelo racional-legal ao paradigma pós-burocrático: reflexões sobre a burocracia estatal. Organizações e Sociedade [online]. v. 13, n. 37, abr./jun., 2006. 
MOTTA, F. C. P.; VASCONCELlOS, I. F. F.; WOOD JR, T. Controle social nas organizações. Revista de Administração de Empresas, v. 33, n. 5, p. 68-87, 1993.

NARDI, H. C. et al. Subjetividade e solidariedade: a diversidade das formas de implicação dos jovens na economia solidária. Psicologia: Reflexão e Crítica, v. 19, p. 320-328, 2006.

OLIVEIRA, F. D. Os sentidos do cooperativismo de trabalho: as cooperativas de mão-de-obra à luz da vivência dos trabalhadores. Psicologia e Sociedade, v. 19, p. 75-83, 2007.

PAES DE PAULA, A. P. Maurício Tragtenberg: contribuições de um marxista anarquizante para os estudos organizacionais críticos. Rev. Adm. Pública, v. 42, p. 949-968, 2008.

PINTO, J. R. L. Economia Solidária: de volta à arte da associação. 1.ed. Porto Alegre: Editora da UFRGS, 2006. 196p.

ROBAQUIM, A.; QUINTAES, R. A. Autogestão: alternativa socialista para o capitalismo. Revista de Administração de Empresas, v. 12, n. 3, p. 96-99, 1972.

ROCHA, D.; DEUSDARA, B. Análise de Conteúdo e Análise do Discurso: aproximações e afastamentos na (re)construção de uma trajetória. Alea, Rio de Janeiro, v. 7, n. 2, dez. 2005.

SINGER, P. Economia solidária: um modo de produção e distribuição. In SINGER, P.; SOUZA, A. R. de. A economia solidária no Brasil: autogestão como resposta ao desemprego. São Paulo: Contexto, 2003. 360p.

Introdução à Economia Solidária. 2. ed. São Paulo: Editora Fundação Perseu Abramo, 2006. 127p.

SOUSA SANTOS, B. de. Um discurso sobre as ciências. 6. ed. São Paulo: Cortez, 2009. 92p.

TOWNLEY, B. Foucault, Power/Knowledge and its relevance for human resource management. Academy of Management Review, v.18, n. 3, p. 518-545, 1993.

TRAGTENBERG, M. Administração, poder e ideologia. 2. ed. São Paulo: Cortez, 1989. 204p.

VENOSA, R. A institucionalização de tipologias organizacionais. Um estudo de caso: a autogestão na Iugoslávia.

Revista de Administração de Empresas, v. 22, n. 2, p. 23-36, 1982.

VOLNOVICH, J. R. Subjetividade e organizações: o discurso neoliberal. In: DAVEL, E; VASCONCELLOS, J. (Org.)

Recursos humanos e subjetividade. 4. ed. Petrópolis: Vozes, 1995. 260p.

WALLERSTEIN, I. Utopística ou as decisões históricas do século vinte e um. Petrópolis, RJ: Vozes, 2003. 